\title{
In memoriam: Dr. Yukihiko Nosé
}

\author{
Tetsuzo Agishi
}

Published online: 15 February 2012

(C) The Japanese Society for Artificial Organs 2012

It is with sincere sadness that I mourn the death of Dr. Yukihiko Nosé, who was a spiritually encouraging senior as a medical researcher and a good friend for over 50 years.

These are my remarks on his death in an attempt to applaud his enormous scientific contributions from the perspective of a close relationship between us.

Dr. Nosé was born in 1932 in Iwamizawa, near Sapporo, Hokkaido, where Hokkaido University, from which he graduated, is located.

After an internship, he became a fellow doctor in the First Surgical Department of Hokkaido University Hospital in 1958, where Professor Jiro Mikami was presiding. He started working on artificial organ research and development, especially artificial livers and kidneys, following Professor Mikami's suggestion. When I joined the same department in 1960, they imprinted on me the illusive idea that artificial organ research is only medicine, nothing else.

Immediately after finishing a Ph.D. course in 1962 with a thesis entitled "Clinical Development of a Coil-type Artificial Kidney Rinsed in an Electric Washing Machine", he moved to Maimonides Medical Center in New York, USA, and started research on "assist-type" artificial hearts with Dr. Adrian Kantrowitz. He moved to the Artificial Organ Department of Cleveland Clinic, Cleveland, Ohio, USA, in 1964 to be a special research fellow where Professor Willem Kolff, a World Godfather of artificial organ development, was presiding, and started working on an implantable artificial heart and an artificial kidney. He became department head in 1972, after Dr. Kolff moved to the University of Utah. I worked with him from 1972 to 1974 in artificial heart and kidney research. It is a very proud memory that a calf implanted with a completely artificial heart survived for 17 days at times when theses such as "Can a calf survive over $100 \mathrm{~h}$ with total artificial heart?" were being discussed at an annual meeting of the American Society for Artificial Internal Organs. In the late 1970s, he started working on apheresis therapy, which was postulated to be a tributary technique from artificial kidneys. We again met by accident and worked together in a variety of international apheresis-related medical societies and associations. In 1987 he moved to Baylor Medical College, Houston, Texas, and worked there until his death on 13 October, 2011.

$\mathrm{He}$ had been a locomotive and world-wide leader in all types of artificial organ research and development from the initiation of clinical applications of such medical techniques as early as the 1960s until such applications became established as routine in the first decade of the 21 st century. Another aspect of his contribution which must also be highly valued is that despite living in USA he took care of many Japanese researchers moving to the USA. From the 1980s until recently there was a difference between situations in everyday life and in research work in Japan and the USA. During this time he gave much valuable advice and made many suggestions to many Japanese researchers who visited his institution. "Gasshou" to Dr. Yukihiko Nosé!

T. Agishi ( $\square)$

Tokyo Women's Medical University, Tokyo, Japan

e-mail: hokksappo@feel.ocn.ne.jp 